\title{
Pregnancy in cardiac disease: clinical, obstetric and anaesthetic concerns
}

\author{
Ravi Jindal ${ }^{1}$, Sukhwinder Kaur Bajwa ${ }^{1}$, Sukhminder Jit Singh Bajwa ${ }^{1}$, Ratika Jindal ${ }^{1}$ \\ Sri Lanka Journal of Obstetrics and Gynaecology 2011; 33: 174-182
}

\begin{abstract}
In the past patients with cardiac disease were advised against pregnancy. With improved cardiac care and better obstetric as well as anaesthetic facilities, pregnant cardiac patients are on rise. Their management involves joint efforts of cardiologist, obstetrician and anaesthetist. Instead of a specific technique, what underlies a successful anaesthesia in cardiac patients is maintenance of haemodynamic stability and avoiding adverse physiological effects of parturition on maternal pathophysiology. Both regional as well as general anaesthesia provide successful outcomes. Vaginal delivery is preferred over caesarean section.
\end{abstract}

Key words: pregnancy, cardiac disease, peripartum cardiomyopathy.

\section{Introduction}

Cardiac disease is the third most common cause of maternal death ${ }^{1}$. Though in early 1900s maternal mortality was high in cardiac disease, now it ranges from $0.5 \%$ to $2.7 \%$. $0.2 \%$ to $4 \%$ of pregnant patients have a cardiac disease. $20 \%$ of such cases have severe cardiac complications ${ }^{2-5}$. Most of the patients having New York Heart Association (NYHA) class I or II status before pregnancy, accomplish pregnancy safely. Exceptions include patients with fixed left-sided obstruction (mitral or aortic stenosis), those with pulmonary vascular disease or aortic valve disease. Patients with NYHA class III or IV are at a higher risk. Assessment of the ability of the abnormal heart to make the necessary adaptations to the major physiological cardiovascular changes occurring during pregnancy, labour and delivery is necessary. One should be able to predict potential trouble in advance both for the mother and the baby, and reduce likely adverse effects (environmental and genetic) on the foetus ${ }^{1}$.

\footnotetext{
${ }^{1}$ Gian Sagar Medical College and Hospital, Banur, Patiala, Punjab, India.

Correspondence: Sukhwinder Kaur Bajwa

E-mail: sukhminder_bajwa2001@yahoo.com
}

Physiological changes in the cardiovascular system in pregnancy include a 50\% increase in blood volume, $40 \%$ increase in cardiac output and a $25 \%$ increase in heart rate by the end of second trimester. There is a fall in systemic vascular resistance (SVR) and pulmonary vascular resistance (PVR). There occurs an increase in myocardial oxygen demand by approximately $50 \%$ during labour ${ }^{1,2,6,7}$.

Vaginal delivery is preferred over caesarean section (CS) ${ }^{5,7}$. The advantages include reduced blood loss and fluid shifts, reduced metabolic demands and stress response and lower incidence postoperative infections and pulmonary complications. Indications for CS include: severe aortic stenosis, aortic dissection, recent myocardial infarction, Marfan syndrome with aortic root involvement and severe heart failure during delivery (The principle is to avoid haemodynamic stress of labour $)^{5}$.

\section{General considerations}

Four main predictors of cardiac events are prior cardiac event (e.g. heart failure, ischemia, dysarrythmia, stroke), baseline NYHA functional class >II or presence of cyanosis, left heart obstruction (mitral valve area $<2 \mathrm{~cm}^{2}$, aortic valve area $<1.5 \mathrm{~cm}^{2}$, left ventricular outflow tract gradient $>30 \mathrm{~mm} \mathrm{Hg}$ by echocardiography) and reduced left ventricular function (ejection fraction $<40 \%$ ). For risk estimation each predictor is assigned one point each. The estimated risks for cardiac event with 0,1 and $>1$ points are $5 \%, 27 \%$ and $75 \%$ respectively ${ }^{4}$.

\section{Predelivery}

The main aims: antepartum stabilisation of the mother's condition (e.g. use of b-blockers, thromboprophylaxis, or pulmonary arterial vasodilators as required), monitoring any for deterioration; and minimizing stress on the cardiovascular system during delivery and the post-partum period. Diuretics, digoxin, and hydralazine, nitrates, or both as vasodilators to offload the left ventricle may be used for heart failure. Assessment for any foetal problems due to various drugs is required ${ }^{6}$.

\section{Intrapartum}

Regional analgesia during labour helps reduce increase in cardiac output and myocardial oxygen 
demand due to pain and anxiety and facilitate instrumental delivery ${ }^{8}$. General and regional anaesthesia (spinal, epidural, or combined spinal-epidural) can all be used for Caesarean section ${ }^{9}$. Cardiovascular stability is the goal ${ }^{7}$. Oxytocin, if required, postdelivery, is given only by infusion ${ }^{10}$. Bolus administration should be avoided. Ergometrine in severe cardiac disease leads to vasoconstriction and hypertension, and increases the risk of myocardial infarction and pulmonary oedema. Therefore, it should be avoided. Carboprost can lead to or exacerbate pulmonary oedema7.

\section{Postpartum}

In the post-partum period, high-level maternal surveillance is required till the main haemodynamic changes resolve. The patient is monitored in a high dependency unit (HDU)/ intensive care unit (ICU) with haemodynamic and fluid therapy monitoring. Congestive cardiac failure may occur in first 24-72 hours ${ }^{11}$. For unstable cardiac conditions, surveillance may be required in hospital for up to 2 weeks ${ }^{7}$. Chest infection or peripartum cardiomyopathy (which may occur anytime from 1 month predelivery up to 5 months post-delivery) may compromise postpartum period ${ }^{9}$. Adequate posto-perative analgesia should be provided. Due to risk of deep vein thrombosis and subsequent embolisation, early ambulation is advised $^{12}$.

\section{Cardiac diseases complicating pregnancy Congenital Heart Disease (CHD)}

$60 \%$ to $80 \%$ of obstetric patients with cardiac disease have a $\mathrm{CHD}^{13,14}$. These may be cyanotic or acyanotic. Some major issues to be looked into in the peripartum period include evidence of $\mathrm{CHF}$ (compensated or uncompensated), pulmonary hypertension, presence of cyanosis and presence of residual ventricular septal defect ${ }^{15-24}$.

\section{Cyanotic CHD}

These include tetralogy of fallot, tricuspid atresia, Eisenmemger syndrome and transposition of great vessels ${ }^{25}$.

Cyanotic lesions have a right to left shunt. Conditions leading to increase in pulmonary vascular resistance (PVR) or a fall in systemic vascular resistance (SVR) should be avoided (Table 1). Uptake of inhalational anaesthetic is reduced leading to prolongation of induction. Onset of intravenous anaesthetic is fast. Nitrous oxide causes rise in PVR and should be used with caution. Air embolism can have disastrous consequences and has to be meticulously avoided. Epidural catheter placement should be done using saline instead of air. Fall in PVR is beneficial. Hence, increasing $\mathrm{FiO}_{2}$ and respiratory rate helps decrease the shunt fraction ${ }^{15-25}$.

Table 1. Factors affecting pulmonary vascular resistance (PVR) ${ }^{25,26}$

\begin{tabular}{ll}
\hline Factors decreasing PVR & Factors increasing PVR \\
\hline Increasing $\mathrm{PaO}_{2}$ & Hypoxia \\
Avoiding sympathetic stimulation with & Sympathetic stimulation due to light anaesthesia and pain \\
deep anaesthesia & \\
Alkalemia & Acidemia \\
Minimising intrathoracic pressure & Increased intrathoracic pressure \\
1. Spontaneous ventilation & 1. Controlled ventilation \\
2. Normal lung volumes & 2. Positive end expiratory pressure \\
3. Low tidal volume & 3. Atelectasis \\
& 4. High tidal volume \\
Hypocarbia & Hypercarbia \\
Pharmacologic method & Pharmacologic method \\
1. Isoprenaline & 1. Epinepherine \\
2. Phosphodiesterase III inhibitor (milrinone) & 2. Norepinepherine \\
3. Prostaglandin infusion-PGI ${ }_{2}$ and PGE & 3. Phenylephrine \\
4. Inhaled nitric oxide & 4. Nitrous Oxide \\
& Hyperthermia
\end{tabular}


Arterial line may be needed. Central venous pressure (CVP) monitoring is reserved for symptomatic patients while pulmonary artery catheter (PAC) placement is anatomically difficult. Transoesophageal echocardiography (TEE) is a useful real time monitor of cardiovascular status, especially under $\mathrm{GA}^{26}$.

\section{Tetrallogy of fallot}

It constitutes $15 \%$ of all congenital cardiac diseases ${ }^{11}$. It comprises ventricular septal defect, pulmonary stenosis/ right ventricular outflow tract obstruction (RVOTO), overriding aorta and RV hypertrophy ${ }^{11,19,25}$. Most pregnant women will have had corrective surgery (closure of the VSD and widening of the pulmonary tract $)^{27}$. Such patients tolerate pregnancy well and are managed like normal obstetric patient alongwith antibiotic prophylaxis and caution for air embolism ${ }^{11,26}$.

\section{Anaesthetic management}

Labour: Epidural analgesia or combined spinal epidural (CSE) technique in first stage using intrathecal opiods followed by titrated dilute bupivacaine solutions prevent rapid SVR changes. Hypotension is treated with phenylepherine (though it causes elevation of PVR) $)^{17,28}$.

CS: Both regional and general anaesthesia can be used $^{11}$. Single shot spinal should be avoided. Epidural anaesthesia with slow titration of local anaesthetic is used $^{29}$. If general anaesthesia (GA) is used, induction with narcotic and etomidate is preferable to avoid haemodynamic changes ${ }^{11,26}$.

Goals: maintain preload (avoid aortocaval compression) and sinus rhythm, avoid increase in PVR and myocardial depressants, maintain spontaneous respiration $^{24}$.

\section{Eisenmenger syndrome}

It is defined as PVR $>800$ dyne per $\mathrm{cm}^{2}$ along with right to left or bidirectional shunt. Symptoms include fatigue, dyspnoea, cyanosis, oedema and polycythemia ${ }^{2,25}$. These patients are prone to thromboembolism ${ }^{2}$.

\section{Anaesthetic management}

Labour: Intrathecal opioids in first stage. Anticoagulation can be a concern. Intravenous patient controlled analgesia is an option. Avoid methergine. Oxytocin and prostaglandins should be used with caution ${ }^{2}$.

Caesarean Section: Subarachnoid block is contraindicated ${ }^{25,26}$. Epidural anaesthesia with slow titrated dose of local anaesthetic can be used ${ }^{2,29}$. However avoid fall in SVR. If GA is used, ketamine and etomidate are preferred. Positive pressure ventilation, however causes increase in $\mathrm{PVR}^{2,25,29}$.

Goals: maintain preload, SVR and sinus rhythm. Avoid increase in PVR and myocardial depressants $^{2,19,30}$.

\section{Acyanotic CHD}

These include atrial septal defect (ASD), ventricular septal defect (VSD), or patent ductus arteriosus (PDA). Shunt is left to right. Patients with small or repaired defects tolerate pregnancy well ${ }^{1}$.

Balance between SVR and PVR determines the shunt fraction. Hence acute changes should be avoided. Avoid air embolism. CVP monitoring is considered in patients with symptomatic heart failure. Arterial catheter may be required in severe cases $2,15,19,31$.

ASD

Small defects $(<5 \mathrm{~mm})$ are haemodynamically insignificant ${ }^{19,21}$. There is right atrial and ventricular dialatation, increased pulmonary blood flow and pulmonary hypertension ${ }^{31}$.

\section{$V S D$}

$90 \%$ VSDs close spontaneously by 10 years of age. Symptomatic patients have to undergo surgical closure $^{19,31}$.

There is left ventricular overload and dialatation in VSD and PDA ${ }^{19}$.

\section{Anaesthetic management}

Epidural anaesthesia is the preferred technique as it reduces SVR to decrease the shunt flow. GA can be used but one should avoid changes in SVR and PVR $^{11,25,26}$

\section{Valvular heart disease}

These comprise $15 \%$ of cases with cardiac disease in pregnancy. Rheumatic heart disease (RHD) is the commonest cause. Regurgitant leisions are generally well tolerated in pregnancy. However, stenotic leisions decompensate more commonly ${ }^{2,11,29}$.

\section{Aortic Stenosis (AS)}

RHD is the most common acquired cause while bicuspid aortic valve is the commonest congenital cause. Symptoms include fatigue, syncope, dyspnoea and angina pectoris ${ }^{11,26}$. 
Severity of $\mathrm{AS}^{33}$

\begin{tabular}{llll}
\hline & Severe & Moderate & Mild \\
\hline $\begin{array}{l}\text { Mean } \\
\text { Transvalvular } \\
\text { pressure } \\
\text { gradient } \\
\text { (mm Hg) }\end{array}$ & $>50$ & $20-50$ & $<20$ \\
$\begin{array}{l}\text { Aortic valve } \\
\text { area }\left(\mathrm{cm}^{2}\right)\end{array}$ & $<0.8$ & $0.8-1.0$ & \\
\hline
\end{tabular}

In the peripartum period patients with severe AS, due to inability to accommodate increased blood volume and tachycardia, experience worsening of symptoms $^{2,34}$.

\section{Anaesthetic management}

1. Labour: Vaginal delivery is preferred in mild to moderate AS. Epidural analgesia with slow titration of opioid and local anaesthetic may be used. However, fall in SVR has to be avoided. In case of hypotension, epinephrine should be avoided as it causes tachycardia. Early analgesia helps avoid stress induced effects ${ }^{26}$.

2. CS: CS is preferred in severe $\mathrm{AS}^{26}$. Single shot spinal is contraindicated in severe $\mathrm{AS}^{35}$. Titrated epidural anaesthesia may be used. For GA, etomidate along with opioids is preferred. Avoid glycopyrrolate, atropine, ketamine ${ }^{11,26,33}$.

Goals: maintain normal sinus rhythm and haemodynamics, avoid bradycardia, tachycardia, fall in SVR and myocardial depression ${ }^{2,33}$.

\section{Mitral Stenosis (MS)}

MS occurs mostly due to RHD. It is one of the most common valvular lesion in pregnancy especially in the developing countries ${ }^{14}$. Signs and symptoms include dyspnoea, palpitations, pulmonary oedema, chest pain, haemoptysis and thromboembolism ${ }^{26}$.

\section{Severity of $\mathrm{MS}^{33}$}

\begin{tabular}{llll}
\hline & Severe & Moderate & Mild \\
\hline $\begin{array}{l}\text { Mean valve } \\
\text { gradient } \\
(\mathrm{mm} \mathrm{Hg})\end{array}$ & $>10$ & $6-10$ & \\
$\begin{array}{l}\text { Mitral } \\
\text { valve } \\
\text { area }\left(\mathrm{cm}^{2}\right)\end{array}$ & $<1.0$ & $1.0-1.5$ & 6 \\
\hline
\end{tabular}

Hyperdynamic cardiac circulation is poorly tolerated during peripartum period. Increased plasma volume leads to pulmonary oedema. Tachycardia decreases left ventricular filling time. Atrial fibrillation (AF) is common ${ }^{36}$. Delivery of baby leads to increased preload due to autotransfusion, predisposing to pulmonary oedema ${ }^{26}$.

\section{Anaesthetic management}

1. Labour: avoid tachycardia due to stress. Thus, labour analgesia is important $t^{35,37,38}$. CSE with intrathecal opioids in the first stage followed by titrated local anaesthetic in second stage is beneficial. Fall in SVR is managed with phenylepherine. Avoid ephedrine unless there is relative bradycardia (Heart Rate $<70)^{26}$.

2. CS: Spinal anaesthesia should be avoided in moderate to severe cases due to acute changes in $\mathrm{SVR}^{26}$. Epidural anaesthesia with titrated doses of local anaesthetic is the preferred technique. Drug of choice for hypotension is low dose phenylepherine (50 to $100 \mu \mathrm{g})^{2,39}$. For GA avoid tachycardia inducing drugs (glycolyrrolate, atropine, ketamine, meperidine, pancuronium). Etomidate is a preferred agent $(0.2$ to $0.3 \mathrm{mg} / \mathrm{KG}$. $\beta$-Blocker (Esmolol 30 to $50 \mu \mathrm{g} / \mathrm{Kg}$ ) and moderate dose opioid (Remifentanil 0.5 to $1 \mu \mathrm{g} / \mathrm{Kg}$ ) should be used. Oxytocin should be used with caution ${ }^{2,11,39}$.

Goals: adequate pain control, maintain sinus rhythm, avoid tachycardia, fall in SVR ${ }^{2,33}$.

\section{Mitral regurgitation (MR)}

Common causes include trauma, bacterial endocarditis, papillary muscle rupture, prosthetic valve dysfunction (acute MR), RHD or myxomatous degeneration ${ }^{26,33}$. Acute MR leads to left atrial volume load, increase in pulmonary pressures as well as pulmonary oedema. Chronic MR causes dialatation of left atrium predisposing the patient to $\mathrm{AF}^{2,35}$. Risk of thromboembolism is increased ${ }^{2}$. Moderate tachycardia, as seen in pregnancy, limits the time for regurgitation ${ }^{26}$.

\section{Severity of $\mathrm{MR}^{33}$}

\begin{tabular}{llll}
\hline & Severe & Moderate & Mild \\
\hline $\begin{array}{l}\text { Area of MR } \\
\text { jet }\left(\mathrm{cm}^{2}\right)\end{array}$ & $>6$ & $3.0-6.0$ & $<3$ \\
$\begin{array}{l}\text { Regurgitant } \\
\text { fraction }(\%)\end{array}$ & $>55$ & $30-50$ & $20-30$ \\
\hline
\end{tabular}




\section{Anaesthetic management}

1. Labour: Epidural analgesia or CSE is preferred as it prevents increase in SVR, promotes forward flow of blood and prevents pulmonary congestion ${ }^{2}$. Early analgesia prevents rise in SVR due to pain $^{34}$.

2. CS: Spinal anaesthesia though not contraindicated, but may be poorly tolerated in severe disease due to acute haemodynamic changes. Bradycardia is poorly tolerated. Ephedrine for hypotension helps avoid bradycardia and promotes slight tachycardia. If GA is required, induction with ketamine and glycolyrrolate is recommended. AF should be promptly treated ${ }^{2,34}$.

Goals: Avoid bradycardia, myocardial depression and increase in SVR, slight tachycardia is preferred ${ }^{2,33}$.

\section{Mitral valve prolapse (MVP)}

Incidence is $10 \%$ to $17 \%$ of all pregnancies and is usually tolerated well ${ }^{40}$. Anaesthetic management is to decrease cardiac output and left ventricular end diastolic pressure (LVEDP) ${ }^{11}$. Perioperative events causing enhanced left ventricular emptying and reducing the size of left ventricle (increased sympathetic activity, decreased SVR, upright posture, hypovolemia) are avoided as they increase the MVP. Goals of management are similar to $\mathrm{MR}^{33}$.

\section{Aortic regurgitation (AR)}

RHD is the commonest cause ${ }^{11,26}$. Symptoms include fatigue, decreased exercise tolerance, pounding heart and orthopnea. Peripartum tachycardia and fall in SVR reduces regurgitant fraction ${ }^{2}$.

\section{Severity of $\mathrm{AR}^{33}$}

\begin{tabular}{llll}
\hline & Severe & Moderate & Mild \\
\hline $\begin{array}{l}\text { Regurgitant jet } \\
\text { area as percentage } \\
\text { of LVOT area }\end{array}$ & $>60$ & $25-59$ & $4-24$ \\
\hline
\end{tabular}

LVOT left ventricular outflow tract

Anaesthetic management and goals are similar to that of $\mathrm{MR}^{26}$.

\section{Prosthetic valves}

Risk of foetal complications (foetal haemorrhage due to maternal anticoagulation and teratogenicity) and maternal complications (thrombo-embolic phenomena, valve failure and bacterial endocarditis) is high in a pregnant patient with a prosthetic valve. Porcine heterografts are preferred for women of child bearing age. Both regional and general anaesthesia can be given safely. Regional anaesthesia is preferred. However, chronic use of heparin may result in thrombocytopenia. Also, continuous anticoagulant therapy is a contraindication for regional analgesia. If $G A$ is required, residual valvular or myocardial dysfunction will influence the choice of anaesthetic drugs. Use of additional monitoring i.e. CVP, PA catheter and A-line is recommended ${ }^{11}$.

\section{Endocarditis prophylaxis in cases with cardiac disease}

There is no consensus regarding endocarditis prophylaxis for obstetric patients with cardiac disease undergoing delivery (vaginal/caesarean). Antibiotics should be considered for those at highest risk of an adverse outcome and, when appropriate, given as the membranes rupture. Intravenous amoxicillin and gentamicin should be considered for women with high-risk anatomy or previous history of endocarditis ${ }^{41}$.

Those at highest risk include ${ }^{41}$

1. Prosthetic cardiac valve or prosthetic material used for cardiac valve repair.

2. CHD if a) unrepaired cyanotic disease (including palliative shunts) b) completely repaired CHD with prosthesis during first 6 months post procedure c) repaired CHD with residual defect.

3. Previous endocarditis.

4. Cardiac transplant recipients developing valvulopathy.

\section{Ischemic heart disease in pregnancy}

Acute myocardial infarction(AMI) occurs in 1 out Of 35,700 deliveries with a mortality of $7 \%^{42}$. Mortality within 2 weeks of AMI is $50 \%^{5}$. Hence, a period of 2 weeks should, preferably be provided before delivery ${ }^{42}$. Most of the cases are due to coronary artery spasm ${ }^{5}$. Use of prostaglandins or methergine is associated with coronary atery spasm. Thus, these should be avoided in patients at risk of AMI. Nitrates help avoid AMI due to coronary artery spasm ${ }^{35}$.

\section{Causes of myocardial infarction during pregnancy or the puerperium ${ }^{1}$,}

Spontaneous coronary artery dissection

Hypertension

Hypercoagulable states

Coronary thrombosis

Inherited thrombophilias

Coronary embolism from: prosthetic mitral or aortic valves the left atrium in mitral stenosis 
the left atrium or ventricle in peripartum or other cardiomyopathy

paradoxical in atrial septal defect or patent foramen ovale or in cyanotic congenital heart disease

the placenta in molar pregnancy or chorion carcinoma

Diabetes mellitus

Advanced maternal age

Oxytocic drugs

Ergot derivatives

Bromocriptine

Severe pre-eclampsia

During the peripartum period coronary artery stenting or thrombolytic therapy may be given if the patient is not about to deliver vaginally or by CS, or is immediately postpartum. Aspirin, $\beta$-blockers and nitrates are used for management of AMI during pregnancy ${ }^{5,26,35,43}$. Percutaneous coronary intervention remains the first choice for treatment ${ }^{8}$.

\section{Anaesthetic management}

Stress on the heart increases manifold during labour and delivery. Epidural labour analgesia helps reduce heart rate (HR) and haemodynamic stress. $\beta$ blockade provides a slower HR. Technique of anaesthesia is not important as long as the haemodynamic stability is maintained ${ }^{26}$.

\section{Cardiomyopathy}

Cardiomyopathy during pregnancy can be peripartum, hypertrophic obstructive or idiopathic dialated cardiomyopathy.

\section{Peripartum cardiomyopathy (PPCM)}

National Heart, Lung, and Blood Institute Working Group (NHLBI) in 1997 defined PPCM as the onset of heart failure within last month of pregnancy or upto first 5 months postpartum in absence of identifiable cause $\mathrm{e}^{7,44}$. Echocardiographic criteria include ejection fraction $<45 \%$, fractional shortening $<30 \%$, and/ or diastolic left ventricular dimension greater than $2.72 \mathrm{~cm} / \mathrm{m}^{2}$. Incidence is $1: 3000$ to $1: 4000$ live births with a mortality of $18 \%-50 \%{ }^{11,26}$.

Signs and symptoms include fatigue, dyspnoea, peripheral oedema, palpitations and pulmonary oedema. Etiology is unknown. It is associated with advanced maternal age, preeclampasia, multigravida, obesity and coronary artery disease ${ }^{35}$.

Peripartum management: immediate delivery, if near term ${ }^{35}$. Management of heart failure includes salt and water restriction, diuretics (frusimide), ionotropic support, afterload reduction. Angiotensin converting enzyme inhibitors are withheld till delivery ${ }^{44}$. Approximately 50\% women recover postpartum. Prognosis depends upon left ventricular function at 6-12 months postpartum ${ }^{44}$. There is high risk of heart failure in subsequent pregnancy ${ }^{45}$.

\section{Anaesthetic management}

1. Labour: Epidural analgesia helps reduce SVR. However, coagulation studies should be done as patient may be on anticoagulant therapy.

2. CS: Both regional (epidural) and GA can be used. If epidural anaesthesia is used, slow titration of local anaesthetic is recommended. For GA, inhalational agents, thiopentone and propofol should be used with caution. Stress response during laryngoscopy and intubation, adverse effects of positive pressure ventilation on venous return and of myocardial depressants should be kept in mind. Opioids help reduce stress response. Invasive monitoring including arterial catheters may be required. CVP or PAC should be used, especially for NYHA class III and IV patients. TEE provides real time cardiac monitoring ${ }^{11,26,46}$.

Goals-avoid myocardial depressants and fluid overload.

\section{Hypertrophic obstructive cardiomyopathy}

This is a genetic disorder with varying degree of left ventricular outflow tract obstruction (LVOTO) ${ }^{26,47}$.

The patients usually tolerate physiological changes of pregnancy. Tachycardia exacerbates LVOTO due to increased contractility and reduction in LV preload and afterload. Therefore, patient is usually on $\beta$ blockers ${ }^{48}$.

\section{Anaesthetic management}

1. Labour: Epidural analgesia helps avoid tachycardia. However, neuraxial blockade should be used cautiously to avoid fall in SVR ${ }^{2,35,48}$.

2. CS: Both regional anaesthesia and GA may be used. However, single shot spinal should be avoided. Hypotension should be treated with phenyepherine $^{48}$.

Goals: avoid tachycardia, fall in SVR, decreased preload, maintain normal to slightly reduced contractility and normal to elevated SVR ${ }^{26}$.

\section{Primary pulmonary hypertension (PPH)}

$\mathrm{PPH}$ is defined as elevated PA pressures (mean pulmonary artery pressure (PAP) $>25 \mathrm{~mm} \mathrm{Hg}$ at rest) 
in absence of primary cardiac disease ${ }^{2,35}$. In the peripartum period right ventricular failure can occur. Thromboembolism is also common during this $\operatorname{period}^{35}$.

\section{Anaesthetic management}

1. Labour: Epidural analgesia is preferred ${ }^{26}$. Oxytocin should be used with caution to avoid fall in SVR and increase in PVR. Avoid carboprost and methergine $^{2,35}$.

2. CS: CS may be required in cases with severe disease with RV failure ${ }^{50}$. Both epidural anaesthesia and GA may be used. However, a slow induction epidural anaesthesia is advised. Vasopressors increase pulmonary artery pressure and should be used with caution ${ }^{49}$. Invasive monitoring includes arterial catheters, CVP/PAC and TEE ${ }^{2,35}$.

Goals: similar to Eisenmenger syndrome ${ }^{26}$.

\section{Obstetric care post cardiac transplant}

Increasing evidence shows that pregnancy is well tolerated by cardiac transplant patient, provided cardiovascular and renal functions are preserved prior to pregnancy ${ }^{2,34,51,52}$. The transplanted heart is devoid of any nerve supply and relies on intrinsic adrenergic receptors. Hence, baseline tachycardia (HR approximately $100 / \mathrm{min}$ ) is present. Heart is unresponsive to vagolytics ${ }^{51,53}$. There is accelerated coronary artery disease, impaired cardiac function and immunosuppression $^{2,34}$. There is increased risk of graft rejection, preterm delivery, hypertension, preeclampsia, fetal growth retardation and dysarrythmia in the peripartum period ${ }^{51}$. Dosage of immunosuppressants may need to be altered due to changes in blood volume ${ }^{26}$. Assessment of cardiac function and graft rejection has to be done by recent echocardiography, cardiac catheterisation and myocardial biopsy $^{2}$. The cardiac transplanted patients tolerate vaginal delivery well. CS should be done only for obstetric reasons ${ }^{54}$. However, the cesarean section rate in transplanted women is high ${ }^{55}$.

\section{Anaesthetic management}

Spinal, epidural and general anaesthesia have all been successfully used for postcardiac transplant patient. Epidural anaesthesia with slow titration to avoid fall in SVR is the preferred approach. Avoid epinepherine in epidural injections to prevent tachycardia. Bradycardia is treated with direct acting sympathomimetics (isoproternol, epinepherine). Hypotension is managed with phenylepherine. Invasive monitoring is avoided due to high risk of infection in immunosuppressed patients. Stress dose steroids have to be given. GA, if required, has to be tailored to maintain haemodynamic status ${ }^{26}$.

Goals: strict asepsis, avoid myocardial depressants, avoid tachycardia, hypertension and aortocaval compression, maintain normal filling pressures ${ }^{26}$.

\section{Conclusion}

Every female, including those with cardiac disease, has a right to enjoy motherhood. Given the complexities of cardiac disease, a pregnant cardiac patient has to be managed by coordinated efforts of the obstetrician, cardiologist and the anaesthetist. We need a good antenatal, intranatal and postnatal care to help such patients complete the peripartal period safely. We also need to strengthen our peripheral health infrastructure to cater to the unique requirements of these patients. Proper orientation of the obstetrician and the anaesthetist to the pathophysiological changes of cardiac disease is absolutely necessary.

\section{References}

1. Oakley C. Overview. In: Okley C, Warnes CA ed. Heart disease in pregnancy, 2nd ed. Massachusetts: Blackwell publishing; 2007.

2. Harnett M, Mushlin PS, Camann WR. Cardiovascular disease. In: Chestnut DH, ed. Obstetric anesthesia: principles and practice, 3rd ed. Philadelphia: Elsevier Science, Mosby; 2004.

3. Siu SC, Semer M, Coleman JM, et al. Prospective multicenter study of pregnancy outcomes in women with heart disease. Circulation 2001; 104: 515-21.

4. McFaul PB, Dornan JC, Lamki H, et al. Pregnancy complicated by maternal heart disease. A review of 519 women. Br J Ostet Gynaecol. 1988; 95: 861-7.

5. vanMook WN, Peeters L. Seve cardiac disease in pregnancy part I: Hemodynamic changes and complaints during pregnancy, and general management of cardiac disease in preganacy. Part II: Impact of cangenital and acquired cardiac diseases in pregnancy. Curr Opin Crit Care 2005; 114: $450-527$.

6. Nelson-Piercy C. Heart disease. In: Nelson-Piercy C, ed. Handbook of Obstetric Medicine, 2nd Edn. Martin Dunitz: Taylor \& Francis Group, 2002.

7. Burt CC, Durbridge J. Management of cardiac disease in pregnancy. CEACP 2009; 9(2).

8. Steer PJ, Gatzoulis MA, Baker P. Heart Disease and Pregnancy. London: RCOG Press, 2006.

9. Boyle RK. Anaesthesia in parturients with heart disease: a five year review in an Australian tertiary hospital. Int $J$ Obstet Anesth 2003; 12: 173-7.

10. Tamhane P, O'sullivan G, Reynolds F. Oxytocin in parturients with cardiac disease. Int J Obstet Anesth 2006; 15: 332-3. 
11. Chohan U, Afshan G, Mone A. Anaesthesia for caesarean section in patients with cardiac disease. J Pak Med Assoc 2006; 56(1); 32-8.

12. Biswas RG, Bandyopadbyay BK, Sarka M, Starkar UK, Gaswami A, Mukhejee P. Perioperative management of pregnant patient with heart disease for caesarean section under anaesthesia. JPMA 2003; 8: 1-7.

13. Williams RG, Pearson GD, Barst RJ, et al. Report of the National Heart, Lung, and Blood Institute Working Group on research in adult congenital heart disease. J Am Coll Cardiol 2006; 47: 701-7.

14. Kuczhowski KM. Labour analgesia for parturient with cardiac disease - what does an obstetrician need to know? Acta Obstet Gynecol Scand 2004; 83: 223-33.

15. Skorton DJ, Garson A Jr, Allen HD, et al. Task force 5: Adults with congenital heart disease: Access to care. J Am Coll Cardiol 2001; 37: 1193-8.

16. Head CE, ThorneSA. Congenital heart disease in pregnancy. Postgrad Med J 2005; 81: 292-8.

17. Heggie J, Kasrski J. The anesthesiologist's role in adults with congenital heart disease. Cardiol clin 2006; 24: 571-85.

18. Touati GD, Vouhe PR, Amodeo A, et al. Primary repair of tetralogy of Fallot in infancy. J Thorac Cardiovasc Surg 1990; 99: 396-402.

19. Lovell AT. Anaesthetic implications of grown-up congenital heart disease. BJA. 2004; 93: 12-39.

20. Nollert G, Fischlein T, Bouterwek S, et al. Long term survival in patients with repair of tetralogy of Fallot: 36 year followup of 490 survivors of the first year after surgical repair. J Am Coll Cardiol 1997; 30: 1374-83.

21. Moodie DS. Diagnosis and management of congenital heart disease in the adult. Cardiol Rev. 2001; 9: 276-81.

22. Brickner ME, Hills LD, Lange RA. Congenital heart disease in adults. Second of two parts. NEJM 2000; 342: 334-42.

23. Deanfield J, Thaulow E, Warnes C, et al. Management of grown up congenital heart disease: The Task Force on the Management of Grown up Congenital Heart Disease of the European society of Cardiology. Eur Heart J 2003; 24: 1035-84.

24. Sameulson PN, Lell WA. Tetrology of Fallot. In lake CL ed. Pediatric cardiac anesthesia, 3rd ed. Stamford: Appleton \& Lange; 1998: 303-14.

25. Maranets I, Hines RL. Congenital Heart Disease. In: Hines RL, Marschall KE ed. Anesthesia and Co-existing Disease, 5th ed. Philadelphia: Churchill Livingstone. 2009: 43-60.

26. Weitzel NS, Gravlee GP. Cardiac disease in the obstetric patient. In: Bucklin BA, Gambling DR, Wlody D ed. A practical approach to obstetric anesthesia, Philadelphia: Lippincott Williams \& Wilkins. 2009: 403-34.

27. Kirklin JW, Blackstone EH, Kirklin JK, et al. Surgical results and protocols in the spectrum of tetralogy of fallot. Ann Surg 1983; 198: 251-65.

28. Veldtman GR, Connolly HM, Orszulak TA, et al. Outcomes of pregnancy in women with tetralogy of fallot. J Am Coll Cardiol 2004; 44: 174-180.
29. Ghai B, Mohan V, Khetarpal M, Malhotra N. Epidural anaesthesia for $\mathrm{C}$ Section in patients with Eisenmenger syndrome. Int J Obstet Anaesthesia 2002; 11: 44-47.

30. Martin JT, Tautz TJ, Antognini JF. Safety of regional anesthesia in Eisenmenger's syndrome. Reg Anesth Pain Med. 2002; 27: 509-13.

31. Brickner ME, Hills LD, Lange RA. Congenital heart disease in adults. First of two parts. NEJM 2000; 342: 256-63.

32. Laura L, Klein MD, Henry L, Galar MD. Cardiac diseases in pregnancy. Clin Obstet Gynecol N Am 2004; 31: 429-59.

33. Herrera A. Valvular Heart Disease. In: Hines RL, Marschall KE ed. Anesthesia and Co-existing Disease, 5th ed. Philadelphia: Churchill Livingstone. 2009: 27-42.

34. Ramsey PS, Ramin KD, Ramin SM. Cardiac disease in pregnancy. Am J Perinatol. 2001; 18: 245-66.

35. Ray P, Murphy GJ, Shut LE. Recognition and management of maternal cardiac disease in pregnancy. BJA 2004; 93 : 428-39.

36. Barash PG, Nardi D, Hammond G, Walker-Smith G, Capuano D, Laks $\mathrm{H}$, et al. Catheter-induced pulmonary artery perforation. mechanisms, management and modifications. J Thorac Cardiovasc Surg 1981; 82: 5-12.

37. Siu SC, Colman JM. Heart disease and pregnancy. Heart 2001; 85: 710-15.

38. Clark SL, Phelan JP, Greenspoon J, et al. Labor and delivery in the presence of mitral stenosis: Central hemodynamic observations. Am J Obstet Gynecol 1985; 152: 984-88.

39. Pan P, D'Angelo R. Anesthetic and analgesic management of mitral stenosis during pregnancy. Reg Anesth Pain Med 2004; 29: 1382-85.

40. Rayburn WF, Fontana ME. Mitral vale prolaspe and pregnancy. Am J Obstet Gynecol 1981; 141: 9-11.

41. Warnes CA, Williams RG, Bashore TM, Child JS, Connolly HM, Dearani JA, et al. ACC/AHA 2008 Guidelines for the Management of Adults with Congenital Heart Disease: Executive Summary: a report of the American College of Cardiology/American Heart Association Task Force on Practice Guidelines (writing committee to develop guidelines for the management of adults with congenital heart disease). Circulation 2008; 118(23): 2395-451.

42. Ladner HE, Danielsen B, Gilbert WM. Acute myocardial infarction in pregnancy and puerperium: A population based study. Obstet Gynecol 2005; 105: 480-84.

43. Lewis, G (ed.). The Con?dential Enquiry into Maternal and Child Health (CEMACH). Saving Mothers' Lives: reviewing maternal deaths to make motherhood safer 20032005. The Seventh Report on Con?dential Enquiries into Maternal Deaths in the United Kingdom. London: CEMACH, 2007. 
44. Pearson GD, Veille JC, Rahimtoola S, et al. Peripartum Cardiomyopathy: National Heart, Lung, and Blood Institute and Office of Rare Diseases recommendations and review. JAMA 2000; 283: 1183-88.

45. Elkayam U, Tummala PP, Rao K, et al. Maternal and fetal outcomes of subsequent pregnancies in women with peripartum cardiomyopathy. NEJM 2001; 344: 1567-71.

46. Bajwa SK, Bajwa SJ, Sood A. Cardiac arrest in a case of undiagnosed dialated cardiomyopathy patient presenting for emergency caesarean section. Anesth Wssays Res 2010; 4: $115-8$.

47. Popescu WM. Heart Failure and Cardiomyopathies. In: Hines RL, Marschall KE ed. Anesthesia and Co-existing Disease, 5th ed. Philadelphia: Churchill Livingstone. 2009: 103-24.

48. Maron BJ, McKenna WJ, Danielson GK, et al. American College of Cardiology/ European Society of Cardiology clinical expert consensus document on hypertrophic cardiomyopathy. J Am Coll Cardiol 2003; 42: 1687-1713.

49. Gandhimathi K, Atkinson S, Gibson FM. Pulmonary hypertension complicating twin pregnancy: continuous spinal anaesthesia for caesarean section. Internal J Obst Anaesth 2002; 11: 301-5.

50. Weiss BM, Zemp L, seifert B, et al. Outcome of pulmonary vascular disease in pregnancy: A systematic Overview from 1978-1996. J Am Coll Cardiol 1998; 31: 1650-7.

51. McKay DB,Josephson MA, Armenti VT, et al. Reproduction and transplantation: report on the AST Consensus Conference on Reproductive Issues and Transplantation. Am J Transplant 2005; 7: 1592-9.

52. Armenti VT, Radomski JS, Moritz MJ, et al. Report from the National Transplantation Pregnancy Registry (NTPR): Outcomes of pregnancy after transplantation. Clin Transpl 2005; 69-83.

53. Akhtar S. Ischemic Heart Disease. In: Hines RL, Marschall KE ed. Anesthesia and Co-existing Disease, 5th ed. Philadelphia: Churchill Livingstone. 2009: 1-26.

54. Scott JR, Wagoner LE, Olsen SL, Taylor DO, Renlund DG. Pregnancy in heart transplant recipients: managment and outcome. Obstet Gynecol 1993; 82: 324-7.

55. Wagoner L, Taylor D, Olson S, et al. Immunosuppressive therapy, management and outcomes of heart transplant recipients during pregnancy. J Heart Lung Transplant 1993; 12: $993-1000$. 